Available online at https://jurnal.stmikroyal.ac.id/index.php/jurdimas

\title{
PELATIHAN PEMANTAPAN PENGOLAH KATA DAN ANGKA UNTUK PEMBUATAN LAPORAN KEPADA PEGAWAI PEMERINTAHAN
}

\author{
Hommy Dorthy Ellyany Sinaga $^{1^{*}}$, Afdhal Syafnur ${ }^{1}$, Novica Irawati ${ }^{1}$ \\ ${ }^{1}$ Sistem Informasi, Sekolah Tinggi Manajemen Informatika dan Komputer Royal \\ email:*omisinaga@gmail.com
}

\begin{abstract}
Training on word processor and spreadsheet is needed for government employees at UPT Pengelolaan Irigasi Asahan Danau Toba in making reports such as annual report, financial report, performance report, and etc. The government employees have had the basic knowledge of using word processor and spreadsheet, but there are still many advanced fiture that never used before to fastened the process of reporting making. The lecturer team of Sekolah Tinggi Manajemen Informatika dan Komputer Royal is making a community service in UPT Pengelolaan Irigasi Asahan Danau Toba in February 2021. Training method is a practical training to allow the participants implement the given knowledge. The training is running well and get the positive result from the participants and the head of UPT Pengelolaan Irigasi Asahan Danau Toba. The training result is shown by enhancement of the ability in understanding and practising the training materials of word processing and spreadsheet for making reporting during the session.
\end{abstract}

Keywords: government employee, reporting; spreadsheet; word processor

\begin{abstract}
Abstrak: Pelatihan pemantapan pengolah kata dan angka sangat dibutuhkan oleh pegawai pemerintahan khususnya di UPT Pengelolaan Irigasi Asahan Danau Toba dalam pembuatan laporan seperti laporan tahunan, laporan keuangan, laporan kinerja dan lain-lain. Para pegawai sudah memiliki pengetahuan dasar tentang pengolah kata dan angka, tetapi masih banyak fitur pada perangkat lunak yang belum diketahui dan dipergunakan untuk dapat mempermudah dan mempercepat pembuatan laporan di instansi terkait. Oleh karena itu, tim Dosen Sekolah Tinggi Manajemen Informatika dan Komputer Royal melakukan kegiatan pengabdian kepada masyarakat dengan memberikan pelatihan kepada para pegawai di UPT Pengelolaan Irigasi Asahan Danau Toba pada Februari 2021. Metode pelatihan diberikan dalam bentuk practical training sehingga para peserta dapat langsung menerapkan pengetahuan yang diperoleh. Pelaksanaan pelatihan berjalan dengan baik dan mendapat respon yang positif dari para peserta dan pimpinan UPT Pengelolaan Irigasi Asahan Danau Toba. Hasil kegiatan pelatihan dapat dilihat dari peningkatan kemampuan peserta dalam memahami dan mempraktekkan secara langsung materi pengolahan kata dan angka untuk pembuatan laporan yang disampaikan selama pelatihan.
\end{abstract}

Kata kunci: laporan; pengolah angka; pengolah kata 
Available online at https://jurnal.stmikroyal.ac.id/index.php/jurdimas

\section{PENDAHULUAN}

Penyusunan laporan adalah merupakan pemenuhan salah satu kewajiban setiap Instansi pemerintah. Ada beberapa jenis laporan seperti laporan tahunan, laporan kinerja, laporan keuangan dan lain-lain. Peraturan Menteri Pendayagunaan Aparatur Negara dan Reformasi Birokrasi Republik Indonesia nomor 53 tahun 2014 tentang penyusunan perjanjian kinerja, pelaporan kinerja dan tata cara reviu atas laporan kinerja Instansi Pemerintah adalah sebagai dasar hukum penyusunan laporan kinerja instansi pemerintahan (Kemenpan, 2014). Agar laporan dapat diselesaikan tepat waktu dan terstruktur rapi maka sumber daya manusia dari instansi pemerintahan harus memiliki kemampuan teknis yang baik khususnya pada jaman sekarang sudah menggunakan alat bantu teknologi komputer agar dapat dihasilkan laporan dengan baik dan tepat waktu sehingga tercipta efisiensi dan efektivitas kerja (Kasemin, 2016).

Adapun alat bantu teknologi komputer yang paling umum digunakan oleh setiap instansi pemerintah maupun swasta dalam pengelolaan administrasi kantor ataupun pembuatan laporan adalah aplikasi pengolah kata dan pengolah angka pada MS. Office. Pada Kenyataannya, banyak pegawai pemerintahan yang belum memahami ataupun menguasai fitur-fitur pada perangkat lunak pengolah kata dan pengolah angka yang hampir selalu dipergunakan pada administrasi pemerintahan.

Termasuk juga identifikasi masalah di UPT Pengelolaan Irigasi Asahan Danau Toba, belum semua pegawai memiliki kemampuan yang handal pada aplikasi pengolah kata dan angka. Masih banyak fitur-fitur yang ada pada aplikasi pengolah kata dan pengolah angka yang belum dimanfaatkan untuk membantu pekerjaan pembuatan laporan.

Kajian terdahulu terkai dengan penelitan ini yaitu pada penelitian (Simangunsong, Sinaga, \& Manurung, 2019) menjelaskan bahwa pegawai negeri pada dinas kependudukan dan catatan sipil kabupaten Samosir masih banyak didapati yang belum mampu menggunakan komputer. Penelitian yang serupa juga disampaikan (Sormin, Sahara, \& Agustina, 2018) Kurangnya pemanfaatan dan penggunaan komputer di desa kecamatan menyebabkan lambatnya kinerja kepala daerah dalam mengelola administrasi desa.

Pada penelitian yang dilakukan (Wedasuwari, Erawan, \& Hayati, 2020) mendapati bahwa di kelurahan Abianse, kepala lingkungan di wilayah kelurahan sudah menggunakan aplikasi pengolah kata dan pengolah angka tetapi pemanfaatan dalam menunjang pekerjaan belum optimal disebabkan kurang pahamnya fitur-fitur yang tersedia. Serta pada penelitian (Nahlan, Amiruddin, \& Sahur, 2019) menjelaskan hal yang sama pada Staf Kantor desa Massamaturu juga diidentifikasi memiliki pengetahuan yang minim akan fitur-fitur MS. Word dan MS. Excel, sehingga Nahlan merasa perlu untuk memberikan pelatihan kepada staf perangkat desa tersebut. Serta pada penelitian (Adi, 2020) mengidentifikasi permasalahan kualitas layanan perangkat desa diakibatkan kurang mahirnya dalam menggunakan aplikasi perangkat komputer dengan baik sehingga dipandang perlu mengadakan pelatihan bagi perangkat desa.

Oleh karena itu, dibutuhkan pelatihan pemantapan pengolah kata dan angka untuk dapat melengkapi kemampuan pegawai di UPT Pengelolaan Irigasi Asahan Danau Toba agar pembuatan 
Available online at https://jurnal.stmikroyal.ac.id/index.php/jurdimas

laporan dapat diselesaikan dengan cepat dan baik.

Pelatihan ini bertujuan untuk membantu mengatasi masalah pengetahuan pemanfaatan fitur yang lebih banyak pada aplikasi pengolah kata dan angka sehingga setelah mengikuti kegiatan pelatihan ini akan dapat meningkatkan pengetahuan dan ketrampilan dalam memanfaatkan fitur-fitur lebih banyak yang dapat mempermudah pegawai dalam membuat laporan. Sehingga lewat pelatihan ini, nantinya instansi akan memiliki tepat orang, tepat pekerjaan dan tepat waktu yang akan mampu mendukung kinerja organisasi. (Niati, Soelistiyono, \& Ariefiantoro, 2019)

\section{METODE}

Pengabdian kepada masyarakat oleh tim dosen Sekolah Tinggi Manajemen Informatika dan Komputer Royal dilaksanakan di UPT Pengelolaan Irigasi Asahan Danau Toba yang beralamat di jalan HOS. Cokroaminoto No. 14 Kisaran. disusun melalui proses perencanaan, persiapan dan pelaksanaan.

Proses perencanaan kegiatan meliputi kegiatan komunikasi dan observasi dengan instansi UPT Pengelolaan Irigasi Asahan Danau Toba yang bertujuan untuk menjelaskan tentang kegiatan Tridharma perguruan tinggi khususnya Pengabdian Kepada Masyarakat, dan melakukan observasi untuk mengetahui apa saja kebutuhan pelatihan bagi para pegawai. Selain itu juga melakukan koordinasi mengenai rencana waktu dan tempat pelak-sanaan kegiatan.

Proses persiapan meliputi kegiatan mempersiapkan surat menyurat sebagai dokumentasi administrasi, pembagian tugas antar anggota dalam tim pengabdian, penyusunan materi pelati- han, mempersiapkan sarana yang dibutuhkan dalam pelatihan nantinya.

Pelaksanaan kegiatan Pengabdian Kepada Masyarakat dilakukan dengan memberikan pelatihan langsung kepada para pegawai UPT Pengelolaan Irigasi. Ketiga dosen menjadi narasumber dengan materi yang berbeda. Ibu Hommy Dorthy Ellyany menyampaikan materi pelatihan pengolah kata, Bapak Afdhal Syafnur menyampaikan pelatihan pengolah angka dan Ibu Novica menyampaikan pelatihan pembuatan presentasi yang baik dan menarik.

Metode yang digunakan yaitu Pelatihan. Penyajian materi disampaikan langkah demi langkah sekaligus para peserta mengikuti dan mempraktekkan langsung apa yang disampaikan oleh pemateri. Jumlah peserta dalam pelatihan ini adalah 20 orang, dimana pada akhir pelatihan, diberikan evaluasi dengan metode praktek langsung kepada para peserta untuk mengukur peningkatan kemampuan dan penyerapan materi yang sudah diberikan. Untuk mengukur tingkat kepuasan peserta terhadap pelatihan yang diberikan, maka tim dosen melakukan survey singkat secara langsung kepada para partisipan.

\section{PEMBAHASAN}

Dikatakan sebagai pelatihan pemantapan karena didasarkan pada hasil observasi pada UPT Pengelolaan Irigasi Asahan Danau Toba, para pegawai sudah memahami dasar penggunaan aplikasi pengolah kata Ms. Word dan pengolah angka Ms. Excel serta Powerpoint sehingga materi yang disampaikan berada pada tingkat kesulitan dengan level menengah.

Pelatihan pemantapan pengolah kata dan angka untuk pembuatan laporan 
Available online at https://jurnal.stmikroyal.ac.id/index.php/jurdimas

di UPT Pengelolaan Irigasi Asahan Danau Toba terbagi menjadi 3 sesi penyampaian materi. Dalam pembuatan laporan, para pegawai belum memahami penggunaan fitur-fitur yang jarang digunakan pada Ms. Word yang justru sebenarnya sangat membantu memudahkan dalam pekerjaan khususnya pembuatan laporan.

Pemateri pertama menyajikan materi pengolah kata menggunakan Ms. Word 2010. Pemateri memberikan naskah struktur laporan yang dicoba untuk dipraktekkan oleh para peserta dengan mengenali fitur find and replace, fitur bullets, fitur page breaks untuk menyisipkan tampilan landscape pada tampilan portrait, mengganti nomor halaman baru, pembuatan tabel, fitur style (Headings untuk pembuatan daftar isi otomatis) (Johar, 2009). Fitur find and replace membantu pegawai untuk memudahkan mencari kata yang akan diganti menjadi kata lain. Fitur bullets membantu dalam pembuatan poin. Penggunaan fitur page breaks dapat menyisipkan halaman dengan tampilan landscape di antara halaman dengan tampilan portrait. Menu page break juga dapat membantu pegawai dalam membuat pergantian format halaman pada satu dokumen yang sama. Menu insert table membantu pegawai dalam pembuatan tabel dengan cepat dan rapi. Fitur style membantu dalam melakukan penomoran bab dan sub bab dengan cara cepat sehingga dapat membuat daftar isi secara otomatis.

Pemateri kedua menyampaikan tentang pemantapan pengolah angka Ms. Excel. Dimana materi yang disampaikan mencakup penginputan data, penjumlahan otomatis, menarik data berkelanjutan secara otomatis, penerapa rumus vlookup dan hlookup. Penginputan data belajar mengenai jenis data yang di- masukkan dan mengubah jenis datanya. Fitur penjumlahan otomatis dimaksudkan agar pegawai dapat melakukan fungsi penjumlahan data yang banyak secara otomatis. Begitu juga dengan menarik data otomatis membantu pegawai menarik data secara berurutan dan otomatis. Penerapan rumus vlookup dan hlookup adalah untuk mengambil nilai dari tabel lain dengan menggunakan kata kunci tertentu baik vertikal maupun horizontal.

Pemateri ketiga menyampaikan tentang pembuatan slide presentasi yang menarik materi yang disampaikan mencakup penerapan design pada slide, fitur animasi, fitur hyperlink dan autoplay. Peserta dilatih untuk memilih templatetemplate design yang menarik. Fitur animasi memampukan peserta untuk membuat slide presentasi dapat bergerak sesuai animasi yang dipilih. Fitur hyperlink membantu peserta melakukan pindah tampilan ke file atau slide lainnya dengan mudah. Fitur autoplay adalah untuk mengubah tampilan slide agar berganti secara otomatis.

Evaluasi pembelajaran dilakukan setelah sesi penyampaian materi. Adapun evaluasi yang dilakukan adalah dengan metode praktek membuat laporan terstruktur seperti saat pelatihan. Hasil dari evaluasi 20 orang peserta, maka tujuh orang peserta memperoleh penilaian sangat baik dan 13 orang memperoleh penilaian baik.

Seperti yang disimpulkan oleh Novica, bahwa pelatihan lewat kegiatan pengabdian kepada masyarakat diyakini akan dapat meningkatkan kualitas sumber daya manusia para peserta pelatihan sehingga nantinya akan dapat membuat dan mempersiapkan laporan Instansi dengan baik (Irawati, Sinaga, \& Siddik, 2018). 
Available online at https://jurnal.stmikroyal.ac.id/index.php/jurdimas

Asih Niati mengatakan bahwa melalui kegiatan pelatihan kepada perangkat desa Mranggen dapat menambah wawasan dan pengetahuan serta meningkatkan kinerja secara lebih maksimal dalam memberikan layanankepada masyarakat sesuai yang diinginkan oleh pemerintah (Niati, Soelistiyono, \& Ariefiantoro, 2019).

Dari hasil pelatihan yang dilakukan kepada Pemdes Kebakalan oleh Ari dkk, peserta pelatihan mendapat pengetahuan dalam membuat surat, mengadministrasikan administrasi desa serta membuat laporan keuangan desa dengan lebih bagus dan cepat (Waluyo, Nasrullah, \& Ediwidjojo, 2020).

Pengabdian berupa pelatihan yang diselenggarakan oleh tim pengabdian Teknik Elektro Unnes kepada pegawai kelurahan Tegalrejo kecamatan Tengaran Kabupaten Semarang juga memberikan manfaat dalam meningkatkan pengetahuan dan ketrampilan penggunaan komputer yang bermanfaat untuk meningkatkan kualitas pelayanan kelurahan terhadap masyarakat (Arief \& Sukamta, 2018).

Secara keseluruhan, kegiatan pengabdian kepada masyarakat berupa pelatihan ini mendapat respon yang sangat baik dari seluruh peserta dan pimpinan UPT Pengelolaan Irigasi Asahan Danau Toba. Peserta dan pimpinan berharap akan ada pelatihan berkelanjutan dari pelatihan ini sehingga mampu menunjang kinerja mereka di instansi terkait.

Setelah evaluasi pembelajaran berakhir, maka tim dosen melakukan survey secara singkat untuk mengetahui tingkat kepuasan peserta terhadap pelatihan yang diberikan. Ada dua pertanyaan yang disampaikan oleh tim dosen kepada peserta yang dapat dilihat pada tabel 1 tingkat kesulitan materi yang diberikan oleh narasumber, dan pada tabel 2 tingkat kemudahan memahami penyampaian materi yang diberikan oleh narasumber.

Pertanyaan untuk tingkat kesulitan materi yang diberikan adalah sebagai berikut: "Dari urutan 1 (tingkat paling mudah) sampai dengan 10 (tingkat paling sulit), menurut anda, tingkat kesulitan materi yang diberikan ada pada angka berapa?"

Peserta memberikan jawaban yang dapat dipaparkan pada tabel 1 .

Tabel 1. Tingkat kesulitan materi yang diberikan

\begin{tabular}{cc}
\hline $\begin{array}{c}\text { Angka } \\
\text { kesulitan }\end{array}$ & Jumlah yang menjawab \\
\hline 1 & 0 \\
\hline 2 & 0 \\
\hline 3 & 0 \\
\hline 4 & 1 orang \\
\hline 5 & 3 orang \\
\hline 6 & 5 orang \\
\hline 7 & 5 orang \\
\hline 8 & 4 orang \\
\hline 9 & 2 orang \\
\hline 10 & 0 \\
\hline
\end{tabular}

Pertanyaan untuk melihat tingkat kemudahan memahami penyampaoian materi yang diberikan oleh narasumber adalah sebagai berikut: "Dari urutan 1 (tingkat paling mudah) sampai dengan 10 (tingkat paling sulit), menurut anda, tingkat kemudahan memahami penyampaian materi yang diberikan ada pada angka berapa?"

Peserta memberikan jawaban yang dapat dipaparkan pada tabel 2 . 
Jurdimas (Jurnal Pengabdian Kepada Masyarakat) Royal

Vol. 4 No. 2, Mei 2021, hlm. 181 - 188

DOI: https://doi.org/10.33330/jurdimas.v4i2.1069

Available online at https://jurnal.stmikroyal.ac.id/index.php/jurdimas

Tabel 2. Tingkat kemudahan memahami penyampaian materi

\begin{tabular}{cc}
\hline $\begin{array}{c}\text { Angka } \\
\text { kesulitan }\end{array}$ & Jumlah yang menjawab \\
\hline 1 & 0 \\
\hline 2 & orang \\
\hline 3 & 5 orang \\
\hline 4 & orang \\
\hline 5 & orang \\
\hline 6 & orang \\
\hline 7 & 0 \\
\hline 8 & 0 \\
\hline 10 & \\
\hline
\end{tabular}

Gambar 1. Pemaparan materi pengolah kata

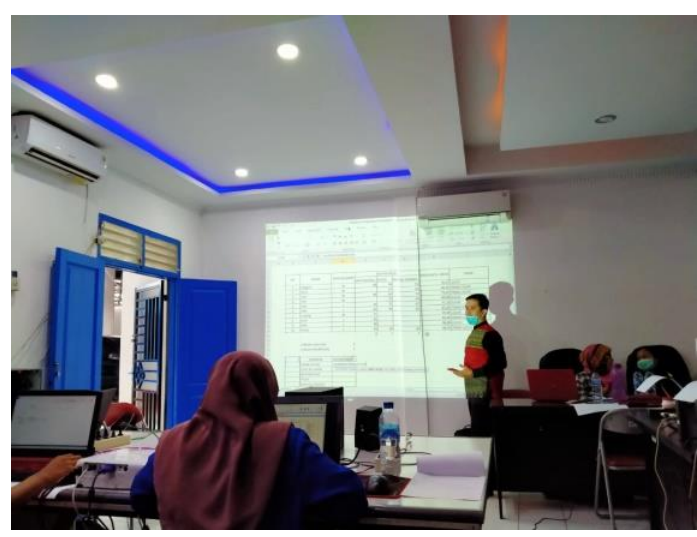

Gambar 2. Pemaparan materi pengolah angka

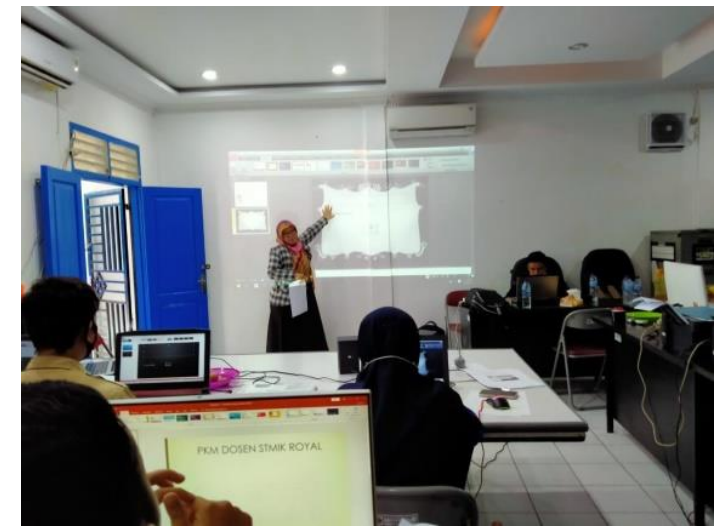

Gambar 3. Pemaparan materi pembuatan presentasi

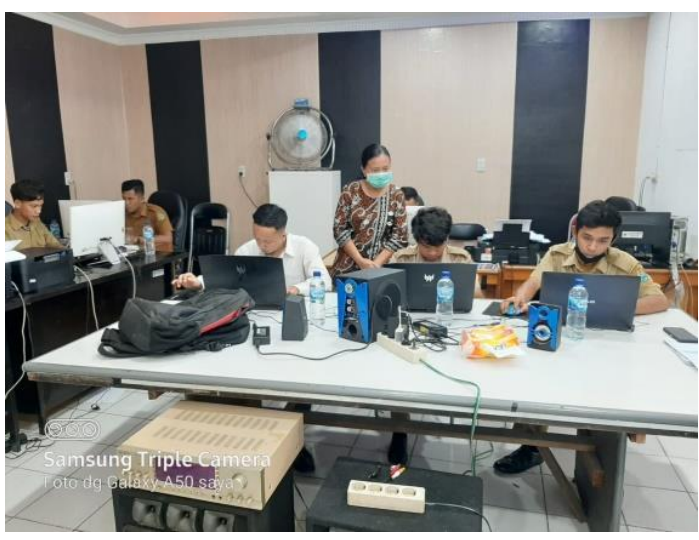

Gambar 4. Evaluasi pelatihan

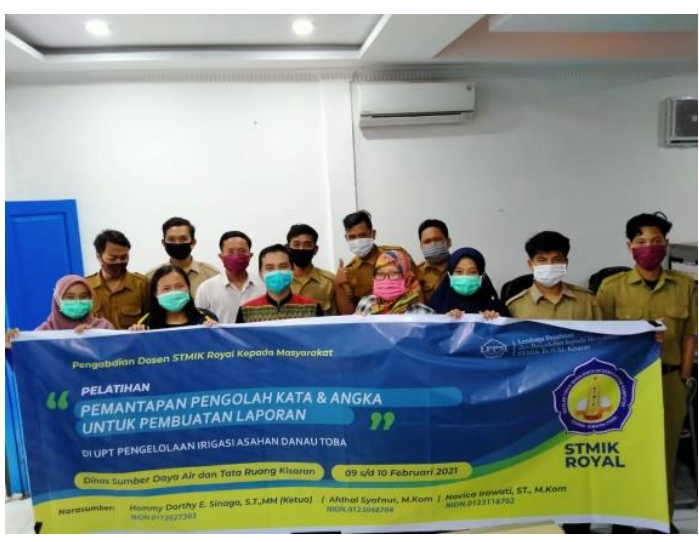

Gambar 5. Foto bersama

\section{SIMPULAN}

Pengabdian kepada masyarakat yang telah dilakukan oleh tim dosen Sekolah Tinggi Manajemen Informatika 
Available online at https://jurnal.stmikroyal.ac.id/index.php/jurdimas

dan Komputer Royal di UPT Pengelolaan Irigasi Asahan Danau Toba, mengambil bagian dalam pelatihan pemantapan pengolah kata dan pengolah angka secara praktek langsung, telah diselesaikan dengan baik dan dapat meningkatkan pengetahuan dan kemampuan para pegawai dalam membuat laporan instansi lebih cepat, lebih rapi dan lebih terstruktur dengan menggunakan fitur-fitur yang lebih banyak pada aplikasi pengolah kata dan pengolah angka.

\section{DAFTAR PUSTAKA}

Adi, I. N. R. (2020). Pelatihan Microsoft Office Bagi Perangkat Desa Wongaya Gede Kecamatan Penebel Kabupaten Tabanan. Parta: Jurnal Pengabdian Kepada Masyarakat, 1(1), 18-21. Retrieved from https://journal.undiknas.ac.id/inde x.php/parta/article/view/2754

Arief, U. M., \& Sukamta, S. (2018). Pelatihan Komputer Untuk Administrasi Dan Keuangan Pegawai Kelurahan Desa Tegalrejo Kecamatan Tengaran Kabupaten Semarang. Jurnal Abdimas PHB, 1(1), 62-66. Retrieved from https://ejournal.poltektegal.ac.id/i ndex.php/abdimas/article/view/70 5

Irawati, N., Sinaga, H. D., \& Siddik, M. (2018). Pembelajaran Teknologi Komputer Bidang Perkantoran Bagi Perangkat Desa di Kecamatan Bunt Pane. Jurdimas Royal, 1(2), 19-22.

Johar, A. (2009). Dasar - Dasar Menggunakan Microsoft Office. Jakarta: PT Elex Media Komputindo.
Kasemin, K. (2016). Agresi Perkembangan Teknologi Informasi. Jakarta: Gramedia Group.

Kemenpan. Peraturan Menteri Pendayagunaan Aparatur Negara dan Reformasi Birokrasi Republik Indonesia No 53 tahun 2014. , (2014). Indonesia.

Nahlan, N., Amiruddin, A., \& Sahur, A. (2019). Pelatihan Penggunaan Ms Office Pada Staf Kantor Desa Massamaturu Kabupaten Takalar. Seminar Nasional Hasil Penelitian \& Pengabdian Kepada Masyarakat (SNP2M), 20-24. Ujung Pandang: Pusat Penelitian \& Pengabdian Kepada Masyarakat (P3M). Retrieved from

http://jurnal.poliupg.ac.id/index.p $\mathrm{hp} / \mathrm{snp} 2 \mathrm{~m} /$ article/view/1615

Niati, A., Soelistiyono, A., \& Ariefiantoro, T. (2019). Pengembangan Kemampuan Sumber Daya Manusia melalui Pelatihan Komputer Microsoft Office Excel untuk Meningkatkan Kinerja Perangkat Desa Mranggen. E-Dimas: Jurnal Pengabdian Kepada Masyarakat. https://doi.org/10.26877/edimas.v10i1.3557

Simangunsong, A., Sinaga, B., \& Manurung, J. (2019). Penyuluhan dan Pelatihan Kemampuan Dasar Komputer Bagi PNS Dinas Kependudukan dan Catatan Sipil Kabupaten Samosir. TRIDARMA: Pengabdian Kepada Masyarakat (PkM), 2(1), 19-25. Retrieved from https://iocscience.org/ejournal/ind ex.php/abdimas/article/view/536

Sormin, M. A., Sahara, N., \& Agustina, L. (2018). Pelatihan Pemanfaatan 
Available online at https://jurnal.stmikroyal.ac.id/index.php/jurdimas

Perangkat Lunak (Microsoft Office Word, Excel, Power Point) Dalam Kinerja Pengolahan Data Di Pemerintahan Desa Bagikepala Desa Se-Kecamatan Batang Angkola. Martabe: Jurnal Pengabdian Kepada Masyarakat, 1(2), 78-82. Retrieved from http://jurnal.um-

tapsel.ac.id/index.php/martabe/art icle/view/449

Waluyo, A., Nasrullah, H., \& Ediwidjojo, S. P. (2020). Pelatihan Penggunaan Apkikasi Microsoft Office (Word, Excel, Power point) 2010 Untuk Peningkatan Kemampuan SDM PEMDES
Desa Kebakalan, Karanggayyam, Kebumen. JURPIKAT (Jurnal Pengabdian Kepada Masyarakat), 1(1), 21-28. Retrieved from https://jurnal.politeknikkebumen.ac.id/index.php/jurpikat/ article/view/273

Wedasuwari, I. A. M., Erawan, D. G. B., \& Hayati, E. (2020). Pelatihan Pemanfaatan Microsoft Office bagi Kepala Lingkungan di Kelurahan Abianbase. WIDYABHAKTI Jurnal Ilmiah Populer, 3(1), 55-61. Retrieved from https://widyabhakti.stikombali.ac.id/index.php/widyabhakti/ article/view/222. 